\title{
Some Biological Properties of Trichothecin, an Antifungal Substance from Trichothecium roseum Link
}

\author{
By G. G. FREEMAN AND R. I. MORRISON \\ Imperial Chemical Industries Ltd., Nobel Division, \\ Research Department, Stevenston, Ayrshire
}

SUMMARY: The production of trichothecin by strains of Trichothecium roseum was greatly increased when nutrients such as yeast extract, malt extract or corn-steep liquor were added to Czapek-Dox medium containing $5 \%(w / v)$ glucose. Ammonium salts, especially ammonium tartrate, were better than nitrate as source of nitrogen, and high trichothecin titres were also obtained with asparagine or glycine as source of nitrogen. Maximum yields of the order of $100 \mathrm{mg} . / 1$. were obtained on a modified Czapek-Dox medium containing ammonium tartrate instead of sodium nitrate and including $5 \%(w / v)$ glucose and $1 \%(v / v)$ of corn-steep liquor, in about 30 days, with $4 \mathrm{~cm}$. depth of medium.

Trichothecin had no antibacterial activity against Staphylococcus aureus, Bacillus subtilis or Bacterium coli. It was active against each of the twenty-seven species of fungi examined. The growth of Penicillium digitatum, the most sensitive species investigated, was completely inhibited at $0.64 \mathrm{mg} . / 1$., and $50 \%$ germination of its spores took place at trichothecin concentrations between 0.30 and $0.75 \mathrm{mg} . / 1$, according to the age of the spores and other factors.

Antagonism between Trichothecium roseum Link and certain plant-pathogenic fungi was reported by Whetzel (1909), Boning (1933), Koch (1934) and Greaney \& Machacek (1935). Koch (1934) stated that $T$. roseum actively parasitized the stroma of Dibotryon morbosum in the black-knot disease of various hosts. The influence of Trichothecium roseum on the pathogenicity of Helminthosporium sativum in experiments with cereals has been observed by Greaney \& Machacek (1935). Antifungal activity of culture filtrates of Trichothecium roseum against Botrytis allii was reported by Brian \& Hemming (1947). The substance responsible for this antagonism was isolated from culture filtrates of the fungus and its chemical properties described (Freeman \& Morrison, 1948), and was given the name 'trichothecin'. The work described here is concerned with the most favourable conditions for the production of trichothecin, and with its biological properties. We first observed that a tenfold dilution of the culture filtrate of a strain of Trichothecium roseum on beer-wort completely suppressed the germination of Penicillium digitatum spores. In cylinder-plates the growth of Aspergillus niger mut. schiemani, Paecilomyces varioti, Fusarium graminearum and Penicillium hagemi was inhibited, though less markedly than that of $\boldsymbol{P}$. digitatum. Antagonism of Trichothecium roseum towards Penicillium spp., both on liquid and solid media, was frequently observed, the mycelia of the latter being ultimately completely overgrown by Trichothecium roseum.

\section{EXPERIMENTAL}

Strains of Trichothecium roseum. Four strains of $T$. roseum were used; they were isolated in this laboratory from specimens of cut wood collected locally. When freshly isolated on beer-wort agar medium all showed the characteristic 
macroscopic appearance of $T$. roseum. The colonies, which were initially white and thinly floccose, rapidly developed a rose pink conidial zone. The erect conidiophores carried terminal clusters of two-celled oval conidia about $20 \times 10 \mu$, each with a nipple-like projection at the point of attachment. Microscopically the various strains were indistinguishable; their various colonial appearances were as follows.

Strain no. F 109. Colonies on beer-wort agar were thinly floccose, white at first, rapidly becoming pink and velvety as conidia developed. On liquid Czapek-Dox medium ( $5 \%(\mathrm{w} / \mathrm{v})$ glucose) supplemented by $1 \%(\mathrm{v} / \mathrm{v})$ corn-steep liquor (CSL), initially produced thick smooth convoluted felt, deep pink in colour. After a number of subcultures on wort agar, the mycelium on liquid medium became largely sterile, compact, white and convoluted with a few small pink conidial areas. This change coincided with a decrease from 30 to $5 \mathrm{mg}$./l. in the trichothecin production on the above medium. The original

\section{Table 1. Maximum trichothecin production and other data of strains of Trichothecium roseum}

Strain no.
F 109
F 198
F 227
F 271

Date isolated

June 1945

August 1946

December 1946

January 1948

\begin{abstract}
Maximum trichothecin production under conditions described in Table 7 on medium $4 \mathrm{~cm}$. deep
\end{abstract} (mg./1.)

25

150

110

20

activity was restored when sodium nitrate was replaced by ammonium tartrate as nitrogen source, but the mycelium remained largely sterile, although conidia developed normally on wort agar.

Strain no. F 198. Colonies on wort agar were thin, pale pink with numerous areas of sterile floccose mycelium. After 3-4 subcultures on wort agar only white floccose sterile mycelium was produced. No antifungal activity was detected when this strain was grown on Czapek-Dox glucose CSL medium, but high concentrations of trichothecin were obtained with the ammonium tartrate-containing medium.

Strain no. F 227. Colonies on wort agar were similar to those of strain F 109, but with occasional floccose sterile areas. On liquid glucose CSL Czapek-Dox medium the mycelium was mainly pink with heavy development of conidia, and the surface was much rougher than that of strain F109. There was occasional development of loose, white floccose areas with delayed conidial production. On the ammonium tartrate-containing medium similar but heavier growth took place.

Strain no. F 271. Colonies on wort agar and conidial production were similar to strain F 109. On the ammonium tartrate-containing medium the mycelium resembled that of strain F 109 in texture, but conidial development took place evenly over the whole surface. 


\section{Assay of trichothecin}

(a) By inhibition of germination of Penicillium digitatum conidia. The basis of the method was described by the Committee on Standardization of Fungicidal Tests of the American Phytopathological Society (1947), and its application to conidia of Botrytis allii by Brian \& Hemming (1945). Penicillium digitatum conidia were used as test material and Czapek-Dox medium containing $5 \%(\mathrm{w} / \mathrm{v})$ glucose at $\mathrm{pH} 4.2$ was employed as germination medium. In preliminary tests, considerable variations were observed in the sensitivity towards the antifungal compound of different batches of spore suspensions (Table 2). This variation

Table 2. Variation in sensitivity to trichothecin of Penicillium digitatum spore suspensions

\begin{tabular}{|c|c|c|c|c|c|c|c|}
\hline \multirow{2}{*}{$\begin{array}{l}\text { No. of } \\
\text { culture }\end{array}$} & \multirow{2}{*}{$\begin{array}{l}\text { Age of } \\
\text { culture } \\
\text { (days) }\end{array}$} & \multicolumn{5}{|c|}{$\begin{array}{c}\text { Percentage germination of spores in presence } \\
\text { of trichothecin (mg./l.) }\end{array}$} & \multirow{2}{*}{$\begin{array}{l}\text { EI 50 } \\
\text { (mg./l.) }\end{array}$} \\
\hline & & $1 \cdot 25$ & $0 \cdot 63$ & 0.31 & $0 \cdot 16$ & 0.08 & \\
\hline 1 & 7 & 10 & 60 & 100 & - & $\ldots$ & 0.75 \\
\hline 2 & & 1 & 10 & 50 & 80 & 100 & $0 \cdot 29$ \\
\hline 3 & & 5 & 50 & 100 & - & - & 0.63 \\
\hline 4 & & 10 & 60 & 100 & - & - & 0.75 \\
\hline 5 & & 5 & 30 & 70 & 100 & - & 0.44 \\
\hline 6 & & 5 & 20 & 50 & 80 & 100 & $0 \cdot 31$ \\
\hline 7 & 14 & 1 & 40 & 80 & 100 & - & 0.53 \\
\hline 8 & & 0 & 20 & 50 & 100 & - & $0 \cdot 38$ \\
\hline 9 & & 5 & 50 & 100 & $\ldots$ & - & $0 \cdot 63$ \\
\hline
\end{tabular}

was overcome by use of a parallel series of standard concentrations of trichothecin with each set of assays, from which the concentration of the substance which permitted $50 \%$ germination (ED 50) was determined for each batch of spores. The ED50 was determined graphically by plotting the probit corresponding to the percentage germination against the logarithm of the concentration (Finney, 1947) and reading the ED50 on the linear response curve thus obtained. The ED50 is cited in the tables in mg./l.

(b) By a cylinder-plate method. The method was an adaptation of the cylinderplate diffusion technique (Abraham, Chain, Fletcher, Gardner, Heatley, Jennings \& Florey, 1941), in which a porcelain cylinder was embedded in beer-wort agar medium, sown with $\boldsymbol{P}$. digitatum spores, in a Petri dish. The cylinder was filled with the test solution and the plate incubated for 3 days at $25^{\circ}$. The dose-response curve for trichothecin (Fig. 1), for concentrations in the range of 1.56-200 p.p.m., shows that there is a linear relationship between diameter of zone of inhibition and the logarithm of trichothecin concentration.

The method compares unfavourably with the spore-germination method. It is less precise because of the diffuse nature of the boundaries of the zones of inhibition, and because the zones are too large to allow both standard and test solutions to be set up on the same $9 \mathrm{~cm}$. plate. It is also slow, since 3 days must elapse before results are obtained.

The data summarized in Tables 3 and 4 were obtained by this method. 


\section{Factors which influence trichothecin production in liquid media}

The influence of a number of factors on trichothecin production in liquid media was investigated. The basal medium was Czapek-Dox containing $5 \%$ $(\mathrm{w} / \mathrm{v})$ glucose, sterilized by autoclaving in $\mathbf{3 5 0} \mathrm{ml}$. quantities (giving $17 \mathrm{~mm}$. depth of medium) in 'Glaxo' bottles. The initial $\mathrm{pH}$ was $5 \cdot 0$. The cultures were

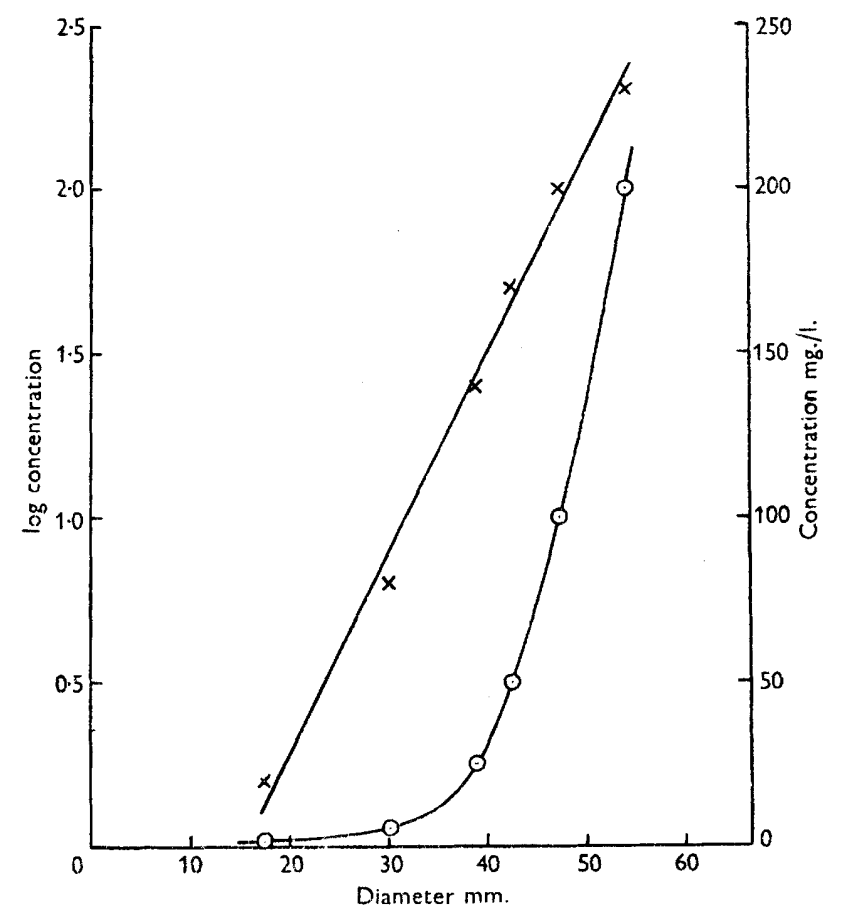

Fig. 1. Relationship between trichothecin concentration and diameter of zone of inhibition of Penicillium digitatum in cylinder-plate assay method. $\odot-\odot$ zone diameter plotted against trichothecin concentration (mg./l.). $\times-\times$ zone diameter plotted against log concentration. Each diameter represents the mean reading from four plates.

inoculated with a suspension of Trichothecium roseum spores from about 7-day beer-wort agar slopes. The cultures were incubated at $25^{\circ}$ in the dark, and samples of the filtrate assayed at intervals. In the absence of added organic nutrients growth was slow and sparse. To produce rapid growth and heavy development of mycelium nutrients such as yeast extract, malt extract, beer wort and CSL were necessary. In preliminary experiments CSL appeared to be most effective in stimulating development of trichothecin.

Corn-steep liquor concentration. The effect of CSL concentrations in the range $0 \cdot 1-2 \%(\mathrm{v} / \mathrm{v})$ at initial $\mathrm{pH}$ values of $4 \cdot 0,6 \cdot 1$ and $7 \cdot 6$ was determined (Table 3 ). In the absence of CSL only traces of activity were produced. Addition of $0 \cdot 1 \%$ $(\mathrm{v} / \mathrm{v})$ resulted in a striking increase of activity, but further increase of CSL above $\mathbf{0 . 2} \%(\mathrm{v} / \mathrm{v})$ produced little further increase in activity. Within the 
range $\mathrm{pH} 4 \cdot \mathbf{0}-\mathbf{7} \cdot \mathbf{6}$, initial $\mathrm{pH}$ had no significant effect on trichothecin production. In the subsequent experiments the various media contained $1 \%(\mathrm{v} / \mathrm{v})$ of CSL.

Table 3. Influence of corn-steep liquor concentration on production of trichothecin by Trichothecium roseum strain F 109 in 'Glaxo' bottle cultures

Trichothecin was assayed by the cylinder-plate method.

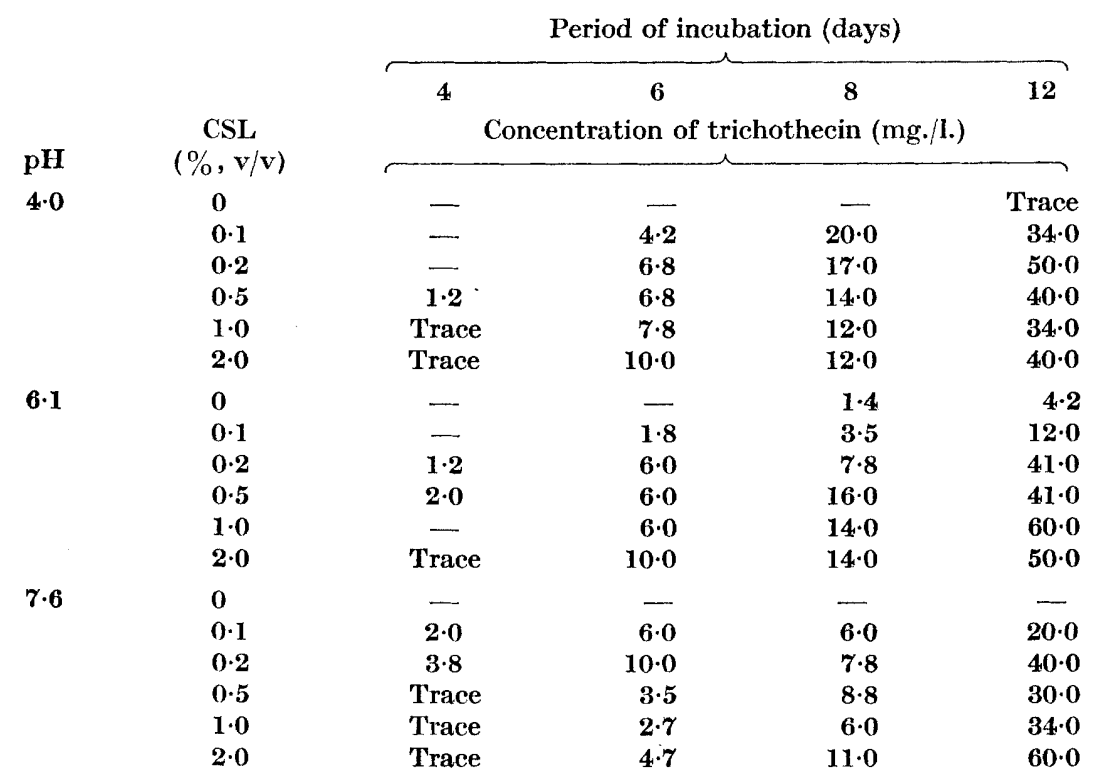

Carbon source. Comparison of glucose, sucrose, lactose and glucose +lactose as carbon sources (Table 4) showed that maximum trichothecin production took place with sucrose and that lactose was unsatisfactory.

Table 4. Effect of source of carbon on trichothecin production by Trichothecium roseum strain F109 in basal medium enriched by various sugars

Trichothecin was assayed by the cylinder-plate method.

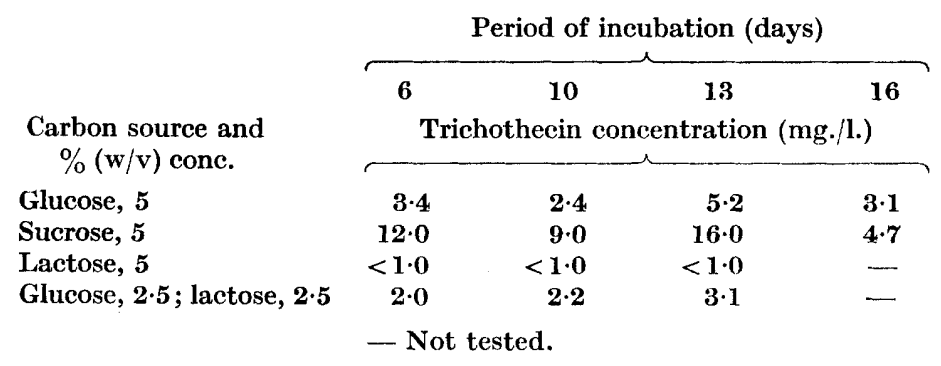

Nitrogen source. The nature of the nitrogen source in the medium had considerable influence on the production of trichothecin. $T$. roseum strain F 227 was grown on a series of media based on the Czapek-Dox formula, containing $5 \%(w / v)$ of glucose and $1 \%(v / v)$ of CSL, in which the normal nitrogen source, 
$\mathrm{NaNO}_{3}$, was replaced by the equivalent amounts of $\mathrm{KNO}_{3}, \mathrm{NH}_{4} \mathrm{NO}_{3},\left(\mathrm{NH}_{4}\right)_{2} \mathrm{SO}_{4}$, ammonium tartrate, asparagine, urea and glycine (Table 5). The ammonium ion was superior to nitrate as a source of nitrogen, except when supplied in the form of ammonium sulphate, in which case the $\mathrm{pH}$ rapidly fell to about $\mathrm{pH} 2$, presumably because of the liberation of sulphuric acid. Ammonium tartrate was the best nitrogen source for trichothecin production and was used in the preparation of trichothecin on a relatively large scale. Asparagine and glycine media both produced high titres of trichothecin, but the maxima were reached more slowly than with ammonium tartrate. Only a trace of activity developed when the medium contained urea as source of nitrogen. In a separate experiment, a medium containing the equivalent concentration of acetamide gave trichothecin production of the same order as that obtained with nitrate nitrogen.

Table 5. Effect of nitrogen source on production of trichothecin in cultures of Trichothecium roseum strain F 227

Sodium nitrate in the Czapek-Dox formula was replaced by equivalent concentrations of other nitrogen sources in media containing glucose $(5 \%, w / v)$ and CSL $(1 \%, v / v)$. Trichothecin was assayed by the spore-germination method. Each result represents the mean of three cultures.

\begin{tabular}{|c|c|c|c|c|c|c|c|c|c|}
\hline \multirow{3}{*}{$\begin{array}{c} \\
\text { Nitrogen } \\
\text { source }\end{array}$} & & \multicolumn{8}{|c|}{ Period of incubation (days) } \\
\hline & & 4 & 7 & 10 & 13 & 4 & 7 & 10 & 13 \\
\hline & $\begin{array}{l}\text { Conc. } \\
\text { (g./l.) }\end{array}$ & \multicolumn{4}{|c|}{ 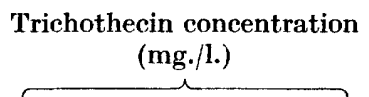 } & \multicolumn{4}{|c|}{ pH } \\
\hline Potassium nitrate & $2 \cdot 5$ & - & $\longrightarrow$ & $2 \cdot 4$ & $\mathbf{3 \cdot 3}$ & $6 \cdot 2$ & $6 \cdot 1$ & $6 \cdot 3$ & $6 \cdot 5$ \\
\hline Ammonium nitrate & $0 \cdot 6$ & $2 \cdot 6$ & $25 \cdot 0$ & $56 \cdot 0$ & $50 \cdot 0$ & $4 \cdot 3$ & $5 \cdot 9$ & $6 \cdot 5$ & $6 \cdot 9$ \\
\hline Ammonium sulphate & $1 \cdot 5$ & $2 \cdot 5$ & $8 \cdot 0$ & $5 \cdot 1$ & $5 \cdot 0$ & $\mathbf{3} \cdot \mathbf{5}$ & $2 \cdot 4$ & $2 \cdot 0$ & $2 \cdot 1$ \\
\hline Ammonium tartrate & $2 \cdot 2$ & - & $25 \cdot 0$ & $34 \cdot 0$ & $77 \cdot 0$ & $6 \cdot 0$ & $\mathbf{5 \cdot 5}$ & $\mathbf{5 \cdot 5}$ & $6 \cdot 5$ \\
\hline Asparagine & $1 \cdot 4$ & - & - & $6 \cdot 8$ & $35 \cdot 0$ & $6 \cdot 5$ & $6 \cdot 4$ & $6 \cdot 3$ & 6.9 \\
\hline Urea & 0.7 & - & - & $0 \cdot 7$ & - & $7 \cdot 0$ & $7 \cdot 5$ & $7 \cdot 3$ & $8 \cdot 0$ \\
\hline Glycine & $1 \cdot 8$ & - & - & $18 \cdot 0$ & $55 \cdot 0$ & 6.0 & 6.6 & 6.5 & $6 \cdot 8$ \\
\hline
\end{tabular}

Glucose concentration. The effect of initial concentrations of glucose in the range $1-20 \%(\mathrm{w} / \mathrm{v})$ was determined in a medium containing $1 \%(\mathrm{v} / \mathrm{v})$ CSL and Czapek-Dox salts in which sodium nitrate was replaced by the equivalent quantity of ammonium tartrate (Table 6). With low concentrations ( 1 or $\mathbf{2} \%(\mathrm{w} / \mathrm{v}))$ of glucose, trichothecin concentrations rose to a maximum after 6 and 10 days, respectively, and thereafter fell equally rapidly to zero. The highest concentration was obtained with $5 \%(\mathrm{w} / \mathrm{v})$ glucose and was only slightly less with $10 \%(\mathrm{w} / \mathrm{v})$ initial glucose. With $20 \%(\mathrm{w} / \mathrm{v})$ initial glucose, both the rate of trichothecin production and the maximum concentration were much lower than with 5 and $\mathbf{1 0} \%(\mathrm{w} / \mathrm{v})$ initial sugar concentrations.

Depth of medium. The maximum practicable depth of medium for trichothecin production and isolation was determined in the medium used in the previous experiment, containing $5 \%(\mathrm{w} / \mathrm{v})$ initial glucose. The results (Table 7) show that although trichothecin concentration attained a maximum more slowly in the deeper media it was at least as high as in the shallower media. 


\section{Biological properties of trichothecin}

Trichothecin had no antibacterial activity against Staphylococcus aureus, Bacillus subtilis or Bacterium coli, at a concentration of $400 \mathrm{mg}$./l. (saturated aqueous solution) and $\mathrm{pH} 7 \cdot 0$, as determined by the cylinder-plate method (Abraham et al. 1941). Its antifungal activity is exhibited against Fungi

Table 6. Effect of initial glucose concentration on trichothecin production

by Trichothecium roseum strain F227

The fungus was grown on the following medium: ammonium tartrate, $2 \cdot 2 \mathrm{~g} . ; \mathrm{MgSO}_{4} .7 \mathrm{H}_{2} \mathrm{O}, 0.5 \mathrm{~g} . ;$ $\mathrm{K}_{2} \mathrm{HPO}_{4}, 1.0 \mathrm{~g}$.; $\mathrm{FeSO}_{4} .7 \mathrm{H}_{2} \mathrm{O}, 0.01 \mathrm{~g} . ; \mathrm{KCl}, 0.5 \mathrm{~g}$.; corn-steep liquor, $10 \mathrm{ml}$; glucose, $10-200 \mathrm{~g} . ;$ water to $1000 \mathrm{ml}$; $\mathrm{pH} 5 \cdot 0$. Trichothecin was assayed by the spore-germination method.

\begin{tabular}{|c|c|c|c|c|c|c|c|c|c|c|c|c|}
\hline \multirow{2}{*}{$\begin{array}{c}\text { Glucose } \\
\text { initial } \\
\text { concentration } \\
\%(\mathbf{w} / \mathbf{v})\end{array}$} & \multicolumn{6}{|c|}{$\begin{array}{l}\text { Trichothecin concentration } \\
\text { (mg./1.) after (days) }\end{array}$} & \multicolumn{6}{|c|}{ pH after (days) } \\
\hline & 4 & 7 & 10 & 13 & 17 & 24 & 4 & 7 & 10 & 13 & 17 & 24 \\
\hline 1 & $19 \cdot 0$ & $20 \cdot 0$ & 11 & $2 \cdot 5$ & - & - & $5 \cdot 0$ & $6 \cdot 5$ & $7 \cdot 1$ & $7 \cdot 7$ & - & - \\
\hline 2 & $24 \cdot 0$ & $30 \cdot 0$ & 39 & $25 \cdot 0$ & 13 & 3 & $5 \cdot 4$ & $6 \cdot 6$ & $7 \cdot 3$ & $7 \cdot 7$ & $8 \cdot 5$ & $9 \cdot 1$ \\
\hline 5 & $24 \cdot 0$ & $45 \cdot 0$ & 33 & $34 \cdot 0$ & 61 & 29 & $5 \cdot 1$ & $6 \cdot 7$ & $7 \cdot 2$ & $7 \cdot 3$ & $8 \cdot 3$ & $8 \cdot 6$ \\
\hline 10 & $27 \cdot 0$ & $41 \cdot 0$ & 45 & $50 \cdot 0$ & 38 & 33 & $4 \cdot 8$ & $6 \cdot 5$ & $7 \cdot 0$ & $7 \cdot 3$ & $8 \cdot 4$ & $8 \cdot 2$ \\
\hline 20 & $1 \cdot 3$ & $4 \cdot 7$ & 13 & $26 \cdot 0$ & 33 & 35 & $4 \cdot 1$ & $6 \cdot 0$ & $6 \cdot 7$ & $7 \cdot 0$ & $\mathbf{8 \cdot 2}$ & $8 \cdot 1$ \\
\hline
\end{tabular}

- Not tested.

Table 7. Effect of depth of medium on trichothecin production by

Trichothecium roseum strain $\mathbf{F} 227$

Medium as in Table 6, with $5 \%(w / v)$ glucose. Trichothecin was assayed by the sporegermination method.

\begin{tabular}{|c|c|c|c|c|c|c|c|c|}
\hline \multirow{3}{*}{$\begin{array}{l}\text { Depth of } \\
\text { medium } \\
\text { (cm.) }\end{array}$} & \multirow{3}{*}{$\begin{array}{l}\text { Volume of } \\
\text { medium per } \\
\text { bottle } \\
\text { (ml.) }\end{array}$} & \multicolumn{7}{|c|}{ Period of incubation (days) } \\
\hline & & 6 & 9 & 13 & 16 & 20 & 27 & 36 \\
\hline & & \multicolumn{7}{|c|}{ Trichothecin concentration (mg./l.) } \\
\hline 0.5 & 100 & $32 \cdot 0$ & $26 \cdot 0$ & 17 & 28 & - & - & 一 \\
\hline $1 \cdot 0$ & 200 & $14 \cdot 0$ & 一 & 72 & 71 & 56 & - & 一 \\
\hline $2 \cdot 0$ & 400 & $6 \cdot 3$ & $25 \cdot 0$ & 55 & $\mathbf{5 8}$ & 74 & 91 & 57 \\
\hline $4 \cdot 0$ & 800 & $2 \cdot 5$ & $9 \cdot 4$ & 30 & 72 & 91 & 111 & 72 \\
\hline
\end{tabular}

Imperfecti, Zygomycetes and Ascomycetes, and the growth of the twenty-seven species of fungi so far examined was inhibited in some degree. Tests in the presence of a range of concentrations of trichothecin $(0 \cdot 13-80 \mathrm{mg} . / \mathrm{l}$., Table 8$)$ revealed wide differences in the sensitivity of different fungi to trichothecin. The growth of Penicillium digitatum, much the most sensitive species examined, was completely inhibited by $\mathbf{0 . 6 4} \mathrm{mg}$. $/$. In contrast, the growth of $\boldsymbol{P}$. notatum, $\boldsymbol{P}$. nigricans janczerwskii and Trichoderma viride was not completely inhibited at a concentration of $80 \mathrm{mg}$./1. Growth of Trichothecium roseum strain F 227 was itself partially inhibited by a trichothecin concentration of $80 \mathrm{mg} . / \mathrm{l}$.

Germination of Penicillium digitatum conidia was virtually suppressed by 
$1.25 \mathrm{mg}$./l. of trichothecin; the ED 50 varied from 0.30 to $0.75 \mathrm{mg}$./l. according to the age and other properties of the conidia (Table 2). The corresponding figures for Botrytis allii spores are $6 \cdot 25$ and $3 \cdot 12 \mathrm{mg} . / \mathrm{l}$.

\section{Table 8. Effect of trichothecin on the growth of certain fungi}

The fungi were seeded on to the surface of beer-wort agar containing varying trichothecin concentrations. After 5 days' incubation at $25^{\circ}$ growth was compared with that obtained on control plates containing no antifungal substance. No growth, 0 ; trace of growth, 1 ; slight growth, 2; good growth, 3; abundant growth (as control), 4.

\begin{tabular}{|c|c|c|c|c|c|c|c|}
\hline & National & & $\begin{array}{l}\text { Re } \\
\text { the }\end{array}$ & $\begin{array}{l}\text { ative } \\
\text { n con }\end{array}$ & rowth & at $\operatorname{tr}$ & $\begin{array}{l}\text { icho- } \\
\text { ng./1.) }\end{array}$ \\
\hline Laboratory & $\begin{array}{c}\text { Collection } \\
\text { of Type }\end{array}$ & & 80 & 16 & $3 \cdot 2$ & $0 \cdot 64$ & $0 \cdot 13$ \\
\hline collection & Cultures & & & Relat & ive gr & rowth & \\
\hline no. & no. & $\begin{array}{c}\text { Organism } \\
\text { Fungi Imperfecti }\end{array}$ & $r$ & & & & \\
\hline F 153 & 982 & Aspergillus fumigatus Fres. & 0 & 3 & 4 & 4 & 4 \\
\hline F 160 & 3308 & A. niger van Tiegh. & 0 & 0 & 4 & 4 & 4 \\
\hline F 181 & 1859 & Cephalosporium longisporum Petch & 0 & 1 & 4 & 4 & 4 \\
\hline F 182 & 2278 & Cladosporium herbarum Link & 0 & 0 & 3 & 4 & 4 \\
\hline F 197 & 一 & Fusarium graminearum Schwabe & 0 & 0 & 3 & 3 & 3 \\
\hline F 180 & 1357 & Helminthosporium sacchari Butl. & 0 & 1 & 2 & 3 & 4 \\
\hline F 17 & - & Paecilomyces varioti Bain. & $\mathbf{0}$ & 3 & 4 & 4 & 4 \\
\hline F117 & 583 & Penicillium caseicola Bain. & 0 & 1 & 4 & 4 & 4 \\
\hline F229 & 3539 & P. citrinum Thom & $\mathbf{0}$ & 1 & 4 & 4 & 4 \\
\hline F 196 & - & $P$. digitatum Sacc. & 0 & $\mathbf{0}$ & o & 0 & 3 \\
\hline F 119 & 593 & P. expansum Link & 0 & 3 & 4 & 4 & 4 \\
\hline F 132 & 584 & P. lilacinum Thom & 0 & 1 & 3 & 4 & 4 \\
\hline F 140 & 3958 & P. meleagrinum Biourge & 0 & 0 & 3 & 4 & 4 \\
\hline F 211 & - & P. nigricans-janczewskii series & 1 & 3 & 4 & 4 & 4 \\
\hline F 143 & 4222 & $P$. notatum Westling & 1 & 4 & 4 & 4 & 4 \\
\hline F 135 & 983 & P. oxalicum Currie \& Thom & 0 & 0 & 4 & 4 & 4 \\
\hline F 133 & 588 & P. roqueforti Thom & 0 & 1 & 4 & 4 & 4 \\
\hline F 234 & 591 & P. spinulosum Thom & 0 & 0 & 4 & 4 & 4 \\
\hline F 214 & 6436 & Stachybotris atra Corda & 1 & 4 & 4 & 4 & 4 \\
\hline F5 & - & Trichoderma viride Pers. ex Fries & 1 & 3 & 4 & 4 & 4 \\
\hline F 227 & - & Trichothecium roseum Link & 2 & 4 & 4 & 4 & 4 \\
\hline & & Ascomycetes & & & & & \\
\hline F 177 & 4020 & Chaetomium convolutum Chivers & 0 & 0 & 2 & 4 & 4 \\
\hline F 268 & 3411 & Neurospora crassa Shear \& Dodge & 0 & 0 & 0 & 4 & 4 \\
\hline B 55 & 742 & Saccharomyces carlsbergensis Hansen & 0 & $\mathbf{0}$ & 1 & 4 & 4 \\
\hline & & Zygomycetes & & & & & \\
\hline F 266 & 1904 & Mucor erectus Bain. & $\mathbf{0}$ & 1 & 2 & 3 & 4 \\
\hline F 264 & 3155 & $\begin{array}{l}\text { Syncephalastrum racemosum (Colm) } \\
\text { Schroet. }\end{array}$ & 0 & 3 & 4 & 4 & 4 \\
\hline F265 & 1127 & Thamnidium elegans Link & 0 & o & 3 & 4 & 4 \\
\hline
\end{tabular}

\section{DISCUSSION}

The isolation of trichothecin and demonstration of its antifungal properties provide fairly conclusive evidence that this compound is responsible for the antagonism exhibited by Trichothecium roseum towards other fungi. Several other crystalline compounds have been isolated from $T$. roseum culture filtrates and will be described elsewhere, but all were devoid of antifungal or anti- 
bacterial activity. Trichothecin is extracted from the filtrates by chloroform, which removes the whole of the antifungal activity. None of the fractions obtained chromatographically, with the exception of the trichothecin-containing fractions, exhibit any antifungal activity. The stability of trichothecin at normal temperatures and over a wide range of $\mathrm{pH}$ (Freeman \& Morrison, 1948) suggests that the compound may persist for sufficiently long in nature to influence the growth of other fungi. In this connexion the frequent occurrence on dead wood of characteristic, virtually pure cultures of $T$. roseum is of interest. Concentrations of trichothecin of the order of $80 \mathrm{mg} . / \mathrm{l}$. partly inhibit growth of $T$. roseum in culture, and old cultures of the fungus slowly lose their antifungal activity.

The antifungal activity originally observed in Czapek-Dox-5\% (w/v) glucose medium proved to correspond to about $10 \mathrm{mg}$. $/ \mathrm{l}$. of trichothecin. The bulk of the work described above was undertaken with the object of improving the yield to provide sufficient quantities of the compound for chemical analysis and degradation studies. No evidence of the mode of antifungal action of trichothecin is yet available; it has, however, been shown that its action is not inhibited by an excess of cysteine (cf. Cavallito \& Bailey, 1944).

We wish to express our thanks to Mr A. J. Baillie for his assistance with the biological assays and to Miss A. McCann for assistance in the isolation of the trichothecin used in this work.

\section{REFERENCES}

Abraham, E. P., Chain, E., Fletcher, C. M., Gardner, A. D., Heatley, N. G., Jennings, M. A. \& Florey, H. W. (1941). Further observations on penicillin. Lancet, ii, 177.

Boning, K. (1933). Zur Biologie und Bekämpfung der Sklerotienkrankheit des Tabaks. Sclerotinia sclerotiorum (Lib.) Massee. Phytopath. Z. 6, 113.

Brian, P. W. \& Hemming, H. G. (1945). Gliotoxin, a fungistatic metabolic product of Trichoderma viride. Ann. appl. Biol. 32, 214.

Brian, P. W. \& Hemming, H. G. (1947). Production of antifungal and antibacterial substances by fungi; preliminary examination of 166 strains of Fungi Imperfecti. J. gen. Microbiol. $1,158$.

Cavallito, C. J. \& Bailey, J. H. (1944). Inactivation of antibiotics. Science, 100, 390.

Committee on Standardization of Fungicidal Tests of the American Phytopathological Society (1947). Test tube dilution technique for use with the slidegermination method of evaluating protective fungicides. Phytopathology, 37, 354 .

Finney, D. A. (1947). Probit Analysis. Cambridge: University Press.

Freeman, G. G. \& Morrison, R. I. (1948). Trichothecin: an antifungal metabolic product of Trichothecium roseum Link. Nature, Lond., 162, 30.

Greaney, F. J. \& MachaceK, J. E. (1935). Studies on the control of the root-rot diseases of cereals caused by Fusarium culmorum (W. G. Sm.) Sacc. and Helminthosporium sativum P.K. \& B. Sci. Agric. 15, 377.

Косн, L. W. (1934). Investigations on the black knot of plums and cherries. Antagonism of Cephalothecium (Trichothecium) roseum and Dibotryon morbosum. Sci. Agric. 15, 80.

Whetzed, H. H. (1909). A fungus living as a parasite upon another fungus. Ont. nat. Sci. Bull. 5, 3.

(Received 9 April 1948) 